\title{
The Self-Schema Model: A Theoretical Approach to the Self-Concept in Eating Disorders
}

\author{
Karen Farchaus Stein
}

\begin{abstract}
Over the last several decades, the self-concept has been implicated as a important determinant of eating disorders (ED). Although considerable progress has been made, questions remain unanswered about the properties of self-concept that distinguish women with an ED from other populations, and mechanisms that link the self-concept to the disordered behaviors. Markus's self-schema model is presented as a theoretical approach to explore the role of the self-concept in ED. To show how the schema model can be integrated with existing work on the self-concept in ED, a framework is proposed that addresses the number, content, and accessibility of the self-schemas. More specifically, it is posited that a limited collection of positive self-schemas available in memory, in combination with a chronically and inflexibly accessible body-weight self-schema, lead to the disordered behaviors associated with anorexia nervosa and bulimia nervosa.

Copyright $\odot 1996$ by W.B. Saunders Company
\end{abstract}

$\mathbf{T}$ THE EATING DISORDERS of anorexia nervosa and bulimia nervosa represent a major health problem among adolescent and young adult women in the United States. Prevalence estimates suggest that up to $2 \%$ of adolescent and young adult women suffer from anorexia nervosa (AN) while an additional $3 \%$ to $6 \%$ suffer from bulimia nervosa (BN) (Drewnowski, Yee, \& Krahn, 1988; Fisher, et al., 1995; Lucas, Beard, O'Fallon, \& Kurland, 1991). The unusual, if not bizarre, constellation of behaviors associated with $\mathrm{AN}$ and $\mathrm{BN}$ exert a devastating toll on the lives of women afflicted with the disorders. As many as $18 \%$ of women with an eating disorder die of medical complications (Patton, 1988; Theander, 1985). Others experience serious physical problems including

From the University of Michigan, School of Nursing, Ann Arbor, $M$.

This study was funded by NINR Grant \# NR03457.

Address reprint requests to Karen Farchaus Stein, Ph.D., RN, University of Michigan, School of Nursing, 400 N. Ingalls, Room 2344, Ann Arbor, MI 48109. E-mail: kfarchau@umich.edu.

Copyright 11996 by W.B. Saunders Company 0883-9417/96/1002-0004\$3.00/0 cardiac arrhythmias, gastrointestinal complications, electrolyte disturbances, and thermoregulatory problems (Halmi, 1987; Herzog, 1992; Palla \& Litt, 1988; Sharp \& Freeman, 1993). In addition to the grave medical consequences, the disorders are also associated with severe emotional distress and impaired social, academic, and occupational functioning (Schlundt \& Johnson, 1990; Toner, Garfinkel, \& Garner, 1986; Thompson, 1994).

Although many important differences between $\mathrm{AN}$ and BN have been identified (Bruch, 1985; Fava, Copeland, Schweiger, \& Herzog, 1989; Wooley \& Kearney-Cooke, 1986), for both disorders, deviations in the self-concept have been thought to play a pivotal role in the etiology. In one of the earliest modern theoretical models of the eating disorders, Bruch (1973) argued that the pathological pursuit of thinness in AN stems from impaired identity formation in adolescence and a lack of clarity in the definition of the self. Since that time, theoretical, empirical, and clinical accounts of both $\mathrm{AN}$ and $\mathrm{BN}$ have consistently focused on attitudes, beliefs, and thoughts about the self as a key source of the eating and weight-related sympto- 
mology (American Psychiatric Association, 1993; Fisher, et al., 1995).

Despite the long-standing interest in the selfconcept in eating disorders a coherent body of empirically supported knowledge that can be used to direct clinical practice, has yet to emerge (Cash \& Brown, 1987). Although there are many possible causes of this limited progress, one important source of difficulty is that research completed to date has tended to be based on clinical models of psychopathology but has lacked a theoretical framework for the self-concept. Historically, theories of the self-concept were highly abstract and general in nature (Markus \& Wurf, 1987; Marsh \& Richards, 1988), providing little direction for those interested in exploring the link between the self-concept and disordered eating behaviors. However, over the last decade, Markus and her colleagues (Markus \& Nurius, 1986; Markus \& Sentis, 1982; Markus \& Wurf, 1987) have developed the schema model of the self-concept that offers a clearer and more concise definition of the construct, while preserving its complex multidimensional nature. As such, the schema model holds potential for strengthening our theoretical understanding of the self-concept deviations associated with $\mathrm{AN}$ and $\mathrm{BN}$, and ultimately will contribute to the development of more refined theoretically-driven intervention strategies.

The purpose of this report is to present the schema model of the self-concept as a theoretical framework that has the potential for explaining how the self-concept contributes to the onset and maintenance of disordered eating and weightrelated behaviors associated with $\mathrm{AN}$ and $\mathrm{BN}$. The report will begin with a review of existing approaches to the self-concept in AN and BN. Then, a brief overview of the schema model will be presented and an integration of this model with existing work on the eating disorders will be discussed. Finally, implications of the schema model for future research and clinical practice will be addressed.

Although the incidence of eating disorders among males has increased in recent years, prevalence data suggest $\mathrm{AN}$ and $\mathrm{BN}$ are disorders primarily afflicting females (American Psychiatric Association, 1993). For this reason, along with the fact that most theoretical and empirical work completed to date has focused on female populations, this paper will focus on the nature of the self-concept in women with an eating disorder.

\section{THE SELF-CONCEPT AND EATING DISORDERS: A REVIEW OF EXISTING MODELS}

$\mathrm{AN}$ is a clinical syndrome characterized by an intense fear of becoming fat, a body weight of $85 \%$ less than expected based on age and height, feelings of fatness in the face of objective emaciation and amenorrhea (American Psychiatric Association, 1994). BN-also a clinical syndrome - is similarly marked by a preoccupation with body size and shape (American Psychiatric Association, 1994). In addition, women with BN engage in food bingeing and purging cycles in which self-induced vomiting, laxatives, diuretics, fasting, and extreme exercise regimens are used.

Although AN and $\mathrm{BN}$ are similar in that they share the symptoms of body weight preoccupations (Vitousek \& Hollen, 1990), the nature of the relationship between the two disorders remains unclear. Some theorists view $\mathrm{AN}$ and $\mathrm{BN}$ on a continuum of eating disorders in which patterns of severe dietary restriction eventually leads to binge/ purging cycles (Boskind-Lodahl, 1976; Fairbarn \& Garner, 1986; Polivy \& Herman, 1985; White, 1991). Others suggest a distinct and clear demarcation between the two disorders arguing that they are marked by unique personality profiles and etiologies (Bruch, 1985; Gordon, 1990; Wooley \& Kearney-Cooke, 1986). More recent approaches to the eating disorders propose that there are three subpopulations of women with an eating disorder including: (1) restricting-type $\mathrm{AN}$, (2) bulimic-type $\mathrm{AN}$, and (3) $\mathrm{BN}$ in individuals of normal weight (American Psychological Association, 1994; Strober, 1981).

Although the debate on the relationship between $\mathrm{AN}$ and $\mathrm{BN}$ continues, models of the self-concept deviations that contribute to the disordered eating behaviors are remarkably similar for both syndromes. For both $\mathrm{AN}$ and $\mathrm{BN}$, three types of self-concept deviations have been addressed including: (1) deficits in identity formation, (2) distortions in body image, and (3) body dissatisfaction and low self-esteem.

\section{Identity Disturbance}

One of the earliest approaches to the self-concept in eating disorders focuses on the process of identity formation in childhood and adolescence. This model, which was initially put forth by Bruch (1973) and later elaborated by other theorists, 
focuses on the dynamics of the parent-child relationship and the resultant developmental deviations in the establishment of a separate and stable sense of the self (Garfinkel \& Garner, 1983). According to Bruch, AN is "a struggle for a self-respecting identity" (Bruch, 1979, p. 255). Highly controlling and perfectionistic parents limit the child's opportunities for autonomous functioning by responding to her based on their expectations for perfection rather than to the child's expressed needs and desires. Within this environment, the child fails to develop a sense of herself as an autonomous, volitional agent but rather relies on her parents as her source of self-definition (Bruch, 1981). The child experiences the self as acting in accordance to demands from others while experiencing deep-seated feelings of being "nothing" (Bruch, 1982). As the child encounters the biological and social challenges associated with adolescence, this lack of selfdefinition gives rise to overwhelming feelings of incompetence, self-doubt, and fears of loosing control. Within this framework, the weight-loss and food-restricting behaviors are a maladaptive way of defining the self and establishing a sense of selfcontrol (Bruch, 1982).

Other theorists who have taken a more culturally based approach to the etiology of eating disorders, similarly view problems in selfhood and identity formation as an important cause of the syndromes (Boskind-Lodahl, 1976; Gordon, 1990). However, in these models, culturally shaped values, norms, and expectations for women undermine the development of an independent, satisfying, and workable definition of the self. An exaggerated adherence to the cultural ideal of women as dependent, accommodating, and beautiful (Boskind-Lodahl, 1976; Striegel-Moore, Silberstein, \& Rodin, 1986), or conflict generated by the competing visions of the ideal woman as both bright, competent, accomplished, pleasing, compliant, and unassertive (Gordon, 1990) become the organizing framework for one's self-definition and impede the processes of self-exploration and discovery. The resultant lack of a authentic identity is viewed as the proximal cause of the disordered behaviors, whereas the cultural context is viewed as the more distal, yet critical cause.

In contrast to the models that focus on external causes of identity problems associated with $\mathrm{AN}$ and BN, Strober (1991) highlights the role of biologically-driven temperamental differences. Building on work that has shown innate differences in temperament or styles of relating to the environment (i.e., patterns of approach-withdrawal to novel stimuli, adaptability to change, intensity of reactivity, and persistence), Strober argues a biological basis to the impaired identity-formation associated with AN. According to this perspective, an innate style of stimulus-avoidance, low novelty seeking, emotional reactivity, and reward dependence interfere with normal exploratory activities necessary to for the development of an agentic and autonomous self.

Common across these various theoretical approaches is the view that the preoccupation with body weight and the disordered eating behavior are a maladaptive attempt to compensate for a disordered concept of the self - one that is immature, impoverished, and incomplete (American Psychiatric Association, 1993). Although this conceptualization of the self-concept in eating disorders is widely accepted within the medical literature, little empirically based knowledge is available to support the claim (for exception, see Schupak-Neuberg \& Nemeroff, 1993). Because the approach is derived from clinical theories of psychopathology, available supporting evidence is primarily in the form of case studies and other clinical vignettes. To date, few attempts have been made to use current self-concept theories and methodologies to more systematically explore this theoretical perspective.

\section{Body Image Distortions}

A second focus of work on the self-concept in eating disorders addresses body-image disturbances. The main hypothesis motivating this work is that the disordered eating behaviors of $\mathrm{AN}$ and BN stem from the subjective experience of one's body-either overall or specific parts-as larger or fatter than it objectively is (Cooper \& Taylor, 1988; Horne, Van Vactor, \& Emerson, 1991; Rosen, 1990). Particularly with AN, body size overestimation is viewed as so central to the disorder that it is identified in the DSM-IV as one of the four essential defining features (American Psychiatric Association, 1994). Although body size overestimation is not one of the diagnostic criteria for $\mathrm{BN}$, it is considered a very common symptom of the disorder that is associated with higher levels of disordered eating, low self-esteem and mood (Cooper \& Taylor, 1988). For both disorders, body size overestimation is thought to be a indicator of poor 
outcome (Bruch, 1981; Touyz, Beumont, \& Collins, 1988).

One popular approach to empirically documenting body-image disturbances in eating disorders is to examine the accuracy of body-size estimations. A variety of procedures including the moving caliper technique (Slade \& Russell, 1973), the image marking method (Askevold, 1975), the distorting photograph technique (Glucksman \& Hirsch, 1969), and paper-and-pencil body ratings (Horne, Van Vactor, \& Emerson, 1991) have been to used to compare the person's subjective estimations of the size of various body parts with objective measurements of the body.

Although the findings of a majority of studies on body-image distortions converge to suggest that women with $\mathrm{AN}$ and $\mathrm{BN}$ overestimate their body size-both overall and specific regions-several questions about the meaning and significance of the findings remain unanswered (Cash \& Brown, 1987; Garner \& Garfinkel, 1981). One important question has to do with the mechanisms underlying the size overestimation (Meermann, Vandereycken, \& Napierski, 1986). Some investigators argue that the body size overestimation is an indicator of underlying perceptual processing abnormalities. This perspective is founded on the theory that women with AN are unable to accurately perceive internal sensations (Bruch, 1973). The impaired ability to perceive and interpret proprioceptive information is believed to stem from the lack of synchrony in the parental-child relationship and is thought to lead to the inability to accurately perceive physiological signals such as hunger and satiety, emotional states such as anger and sadness, and information about one's body boundaries and shape (Strober, 1981). Other investigators suggest that the body estimation techniques measure structural distortions or aberrations in the established mental representations about the self (Garner \& Garfinkel, 1981). According to this perspective, the individual's mental representation of her body is inaccurate and too large. Although a variety of causes of this inaccurate representation have been posited $(\mathrm{Fa}-$ bian \& Thompson, 1989), one of the more popular hypotheses is that the body image was formed during a period when the individual was heavier and the representation failed to accommodate to the thinner body size (Crisp \& Kalucy, 1974; Wooley $\&$ Wooley, 1985). Finally, other investigators suggest that the body estimation techniques may actually tap a variety of motivational factors, such as denial of illness or experimenter demand, rather than perceptual or cognitive aspects of body image (Garner \& Garfinkel, 1982; Hsu, 1982).

Another important question associated with bodyimage research focuses on the role that body-size overestimation plays in the dysregulated eating and weight-related behaviors associated with $\mathrm{AN}$ and BN. Studies have shown that body-size overestimation and accompanying subjective feelings of fatness do not reliably distinguish women with eating disorders from other populations without these disorders, including asymptomatic controls, pregnant women, obese women, and those who engage in subclinical levels of disordered eating behaviors (Casper, Halmi, Goldberg, Eckert, \& Davis, 1979; Cooper \& Taylor, 1988; Strober, Goldenberg, Green, $\&$ Saxon, 1979). The pervasiveness of body-size overestimation in populations of women without eating disorders (Rodin, 1984) raises important questions about how body-image disturbance causes severe dysfunctional behaviors in some subsamples of women, whereas others function normally in the domain. Despite the long-standing interest, the source of body-size overestimation and the mechanisms to account for the linkage with the disordered behaviors remain unclear.

\section{Self-Esteem Disturbances}

The third type of self-concept deviation that has been linked to $\mathrm{AN}$ and $\mathrm{BN}$ is a disturbance in attitudes toward the self. The two attitudes most commonly addressed in the eating-disorder literature include body satisfaction and global selfesteem. Body satisfaction is an intuitively appealing construct that generally refers to the level of positive versus negative feelings towards the physical self (Rosen, 1990). Operational definitions of the construct range from statements about the extent to which one likes specific parts of the body (i.e., hips, bust, or face) or the overall physical self; evaluations of one's body size, again either specific parts or overall body; or the degree of discrepancy between one's perceived size and desired size. Global self-esteem is defined as the level of satisfaction with one's overall self and is typically measured with a paper-and-pencil questionnaire such as the Rosenberg Self-Esteem Scale (Rosenberg, 1965).

Despite the lack of consistency in the definitions of body satisfaction, studies have consistently 
shown that women with an eating disorder evaluate their bodies more negatively than women without eating disorders (Cash \& Brown, 1987; Rosen, 1990). In addition, they report lower global selfesteem than women without disorders (Attie \& Brooks-Gunn, 1989; Huon \& Brown, 1984; Williams, et al., 1993). However, with results similar to body-size overestimation, other populations of women have also been found to have high levels of body dissatisfaction and low self-esteem (Rodin, Silberstein, \& Streigel-Moore, 1985). These findings, along with those of studies that suggest that low self-esteem is also associated with other psychiatric illness that are prevalent in women such as depression (Beck, 1967), suggest that negative attitudes towards the self are not pathognomonic to eating disorders. Rather, low self-esteem may be only part of a larger constellation of self-concept deviations associated with the disorders.

\section{Summary and Critique}

Over the last few decades, considerable effort has been directed toward furthering our understanding of the nature of the self-concept in eating disorders. Diverse theoretical and methodological orientations have been used to explore self-concept deviations and have contributed to the establishment of a broad base of knowledge pointing to the importance of thoughts, images, and attitudes about the self in patients with AN and BN. Yet despite the progress that has been made, continued efforts are needed to move our understandings to a more refined, comprehensive, and integrated level.

A common problem across the existing work on eating disorders is the lack of a theoretical model of the self-concept. This gap, found both in the theoretical models of the eating disorders and in the empirical work, has impacted the emerging body of knowledge in several important ways. First, the lack of theoretical definitions of the self-concept constructs has made the identification of meaningful and appropriate operational definitions difficult and has impeded the empirical investigation of rich and important clinical theories. Second, the lack of a theoretical model of the self-concept has interfered with the specification of the mechanisms to link the self-concept with the disordered-eating behaviors. For example, although there is considerable empirical evidence suggesting women with an eating disorder overestimate their body size and have low self-esteem, currently we have limited understanding of exactly how these aspects of the self-concept lead to the specific patterns of disordered eating associated with AN and BN. Finally, the lack of a comprehensive model of the selfconcept has led to a tradition of research that focuses on single, isolated aspects of the selfconcept such as identity, body image, and selfesteem but has yet to consider how these various aspects may function together to contribute to the behaviors (Keeton, Cash, \& Brown, 1990). The findings of studies that show certain self-concept deviations are found not only in populations of women with eating disorders but other populations of women as well, raise an interesting possibility that a constellation of self-concept deviations may be necessary for the formation and maintenance of the eating disorder symptomology. A comprehensive theoretical model of the self-concept may facilitate consideration of how various aspects function together to motivate and regulate the disordered-eating behaviors.

\section{THE SCHEMA MODEL OF THE SELF-CONCEPT}

The schema model of the self-concept, a contemporary approach to the study of the self developed within the field of cognitive social psychology, is based on the assumption that behavioral responses to stimuli are mediated through an internal system of knowledge structures sometimes referred to as schemas (Goldfried \& Robins, 1983; Markus \& Zajonc, 1985). Schemas are organizations of knowledge that are constructed through interaction with the environment and reflect the person's construal of an object or event. Once schemas are formed, they are stored in long-term memory and act as the foundation for the processing of subsequent interactions with the environment (Taylor \& Crocker, 1981). Although schemas may be formed around any aspect of the environment, either social or asocial, Markus (1977) posits that to process the vast array of self-relevant stimuli routinely encountered, people construct knowledge structures about the self, referred to as self-schemas.

\section{Self-Schemas}

Self-schemas are stable and enduring memory structures about the self that integrate and summarize a person's thoughts, feelings and experiences about the self in a specific behavioral domain (Markus \& Sentis, 1982). Self-schemas can be formed around any aspect of the person, including 
physical characteristics, social roles, personality traits, skills, competencies, and interests. They are established in domains that the individual values, and they reflect the time and effort invested in the domain (Markus, 1977). To date, studies have documented the availability of self-schemas in a variety of behavioral domains including body weight (Markus, Hamill, \& Sentis, 1987), exercise (Kendzierski, 1988), sex roles (Markus, Crane, Bernstein, \& Siladi, 1982), independence (Markus, 1977; Stein \& Markus, 1990), and academic performance (Stein, 1994).

Self-schemas have been compared with the knowledge structures of experts in a specific domain, such as chess (Caire, 1994). That is, they are highly elaborated, well-organized, and enduring organizations of knowledge. Like other expert knowledge structures, self-schemas include not only declarative knowledge about what the self "is" but also procedural rules, strategies, and routines that direct and regulate behavior in the domain (see Cantor, 1990; Greenwald \& Pratkanis, 1984 for reviews). Self-schemas are the cognitive framework through which social stimuli are perceived, interpreted, and recalled (Goldfried \& Robbins, 1983; Greenwald, 1980; Markus \& Wurf, 1987). Furthermore, because self-schemas include procedural knowledge, the person with a selfschema in the domain has a rich repertoire of behaviors available that enables efficient, competent, and consistent functioning in the domain (Cantor \& Kihlstrom, 1987). It is these functional properties of the self-schemas that link them to behavior.

\section{The Total Self-Concept}

Another advantage of the schema model is that it leads to a richer and more complex definition of the self-concept. Historically, the self-concept was conceptualized as a single unitary entity that reflected one's overall evaluation of the self (i.e., global self-esteem) (Markus \& Wurf, 1987; Woolfolk, Novalany, Gara, Allen, \& Polino, 1995). Within the schema model, however, the self-concept is defined as a complex system of cognitions about the self. The self-concept refers to the person's total collection of cognitions about the self that are articulated in memory including the self-schemas and other less fully elaborated images of the self (Cantor \& Kihlstrom, 1987; Greenwald \& Pratkanis, 1984; Markus \& Wurf, 1987).
Based on the schema model, several important sources of individual difference in the self-concept can be identified including: (1) the number of schemas in the self-concept, (2) content of selfschemas, (3) evaluative attitudes associated with the self-schemas, and (4) accessibility of the selfschemas.

Number of schemas included in the self-concept. Studies have shown that people vary according to the number of self-schemas elaborated in memory (Franks, 1994; Stein, 1995a; Stein, Markus, \& Roser, 1995). Whereas some individuals have many domains that are core or central to their selfdefinition, others have relatively fewer. This difference in the elaboration of the self-concept has been shown to be related to such things as age, developmental stage, education and presence of psychopathology (Harter \& Monsour, 1992; Franks, 1994; Stein, 1995a). Furthermore, individual differences in the number of self-schemas included in the self-concept have been linked to emotional and behavioral outcomes including depression, poor self-esteem (Woolfolk, Novalany, Gara, Allen, \& Polino, 1995), and inability to adapt to stress (Linville, 1987).

Content of the self-schemas. Another important source of individual difference is in the content of the self-schemas included in the self-concept. People vary not only according to the number of self-schemas, but also in the particular domains that are claimed as part of the self (Deux, 1991; Stein, Markus, \& Roeser, 1995). Studies have shown that people differ according to whether the domains of health, exercise, and body weight are included as a part of the self-definition, and this source of individual difference has been linked to a number of health-related behavioral outcomes (Hooker \& Kaus, 1992; Kendzierski, 1988; Markus, Hamill, \& Sentis, 1987).

Evaluative attitudes associated with the selfschemas. Another important source of individual difference is the positivity/negativity of the evaluative attitudes towards the self. In addition to the overall evaluation of one's worth, people also have stable attitudes reflecting their feelings of worth in each of the behavioral domains that comprise the self-concept (Harter, 1990). Studies have shown that people evaluate themselves differently in each behavioral domain that comprises the self-concept and that these domain-specific self-evaluations serve as the foundation that gives rise to one's overall 
level of self-satisfaction (Marsh, 1986; Pelham and Swann, 1989; Showers, 1992).

Accessibility of the self-schemas. Accessibility refers to the readiness and ease with which a specific cognition is activated in working memory and used in information processing (Higgins \& King, 1981). Availability refers to whether a cognition is articulated in memory (Bruner, 1957). Individuals differ not only according to the array of cognitions about the self available in memory, but also according to the accessibility of a given cognition. Some cognitions may be chronically accessible in working memory and therefore, persistently used as the framework for the processing of stimuli. Others vary in their accessibility, depending on the social context for activation (Higgins \& King, 1981).

Markus has used the construct of the working self-concept to describe the dynamically changing collection of self-cognitions active in working memory (Markus \& Kunda, 1986). The working self-concept refers to the subset of self-cognitions accessible in working memory at a given point in time. Whereas some self-cognitions may be chronically activated in the working self-concept, other less fully elaborated self-cognitions vary in their accessibility in response to features of the internal and external environment.

Studies have shown that accessible cognitions play an important role in shaping the processing of social information. Which dimensions of a stimulus that are attended to, encoded in memory, and recalled are dependent on the schema accessible in working memory (Higgins \& King, 1981). Individuals with an accessible schema in a domain are not only more likely to selectively attend to aspects of a social stimulus that are consistent with it but in addition, when a stimulus is vague, are likely to use the accessible cognition to interpret and assign meaning to the event (Bargh, Lombardi, \& Higgins, 1988; Markus, Smith, \& Moreland, 1985).

The accessibility of a cognition is a function of features of both the internal and external environment (Markus \& Kunda, 1986). Factors that impact accessibility include: (1) expectations of the likelihood that the stimulus will match the category; (2) current motivation, goals, or need states; (3) recency of activation; (4) frequency of activation; and finally, (5) distinctiveness of the attributes of the cognition (Higgins \& King, 1981).

\section{AN INTEGRATION OF THE SCHEMA MODEL WITH EXISTING WORK ON THE SELF-CONCEPT IN EATING DISORDERS: A PROPOSED MODEL}

In this section, a model of the self-concept in eating disorders will be proposed. The purpose of presenting this model is to show how the schema framework can be integrated with existing theoretical and empirical work to form a comprehensive model of self-concept deviations associated with $\mathrm{AN}$ and BN. Within this proposed model, three aspects of the self-concept are addressed including the number, content, and accessibility of selfschemas. More specifically, it is suggested that a limited collection of positive self-schemas available in memory, in combination with a chronically and inflexibly accessible body-weight self-schema, together lead to the onset and maintenance of the disordered behaviors associated with $\mathrm{AN}$ and $\mathrm{BN}$.

\section{The Total Self-Concept}

Within the schema model, the identity disturbance and lack of self-definition thought to be an important part of AN and BN could be conceptualized in terms of the number of positive selfschemas included in the self-concept. The feelings of self-doubt, incompetence, low self-esteem, and fear of loosing control that typify women with AN and BN (Gordon, 1990; Thompson, 1994) may actually reflect the lack of a broad and diverse collection of positive self-schemas available in memory.

Given that self-schemas include both declarative and procedural knowledge, the availability of many positive self-schemas in memory may be considered an internal resource that facilitates a successful transition into adulthood. An adolescent who has many positive self-schemas available in memory will have a clearer and more stable view of the self and a broader repertoire of behavioral strategies that can be used to give form and meaning to behavior (Markus, Cross, \& Wurf, 1990). As the biological and social transitions of adolescence are encountered, the individual who has many positive self-schemas will have a more diverse and flexible collection of behaviors that can be brought to bear on the problems and challenges encountered.

In contrast, the person who has few positive self-schemas elaborated within the self-concept will have fewer skills available to effectively cope 
with challenges and will be more likely to experience feelings of confusion, frustration, and incompetence. As suggested by Bruch (1973), in an attempt to relieve distress and establish a sense of identity and self-worth, the person with few positive self-schemas may assign unusual importance to her body weight self-conceptions. From this perspective, the impoverished field of self-schemas may be viewed as a vulnerability, which increases the risk that the body-weight self-schema will become the primary source of self-definition.

The constrained field of positive self-schemas may be the result of two different developmental trajectories. In some cases, the lack of a diverse array of positive self-schemas may reflect an actual deficit in development, such that positive knowledge structures about the self were never formed. Many of the etiologic factors cited in the medical literature, such as the highly controlling and restrictive parental relationship (Bruch, 1973) and the cautious, perfectionist personality styles of the child herself (Strober, 1991), may limit opportunities for exploration and experimentation in a variety of social and competency-based arenas. Because the enactment of relevant behaviors and the related evaluations made by oneself and others are central to the construction and subsequent elaboration of self-schemas (Cantor \& Kihlstrom, 1987), individuals who have a limited range and depth of experience will have fewer opportunities to develop positive self-schemas. As a result, the person may enter adulthood with few positive selfschemas elaborated in memory.

In other cases, positive self-schemas may have been formed earlier in development but may become disorganized and dysfunctional in response to a stressful life event. In these cases, the constrained array of positive self-schemas does not reflect a developmental deficit but rather an acute cognitive response to a stressor. This breakdown may be similar to what has been described as a "collapse of the person's world view" (Silver, Boon, \& Stone, 1983). Certain life events, such as divorce or separation from parents, may be so disruptive to the person's core self-conceptions that the total selfdefinition is threatened. During such periods of destabilization of the self-system, existing selfschemas may become fragmented and disorganized, and functionally, the individual may not have accessible the network of self-relevant expertise.

\section{The Body-Weight Self-Schema}

Among the important features of the selfconcept that may distinguish women with an eating disorder from other women with identity disturbances and low self-esteem may be the availability of a body-weight self-schema (Vitousek \& Hollon, 1990; Markus, 1990; Striegel-Moore, McAvay, \& Rodin, 1986). The body-weight schema has been defined as a collection of cognitive and affective representations that focuses on one's body shape and size (Markus, Hamill, \& Sentis, 1987). Like other self-schemas, the body-weight schema is constructed within the social environment and reflects evaluations and categorizations made by oneself and others. However, unlike schemas that focus on abstract features of the self, the bodyweight schema is thought to include not only semantic knowledge but also proprioceptive and imaginal information as well (Markus, Hamill, \& Sentis, 1987; Wooley \& Kearney-Cooke, 1986).

Although all people have at least a rudimentary organization of knowledge about their body weight available in memory (Schilder, 1950), some people who assign particular importance to their body weight have a more elaborated and salient knowledge structure about themselves in the domain (Markus, Hamill, \& Sentis, 1987). Within a sample of objectively overweight women, Markus found that people vary according to the availability of an overweight self-schema. Furthermore, this source of individual difference had a significant impact on the processing of stimuli relevant to the domain. For example, individuals with overweight selfschemas not only processed information relevant to their self-definitions more efficiently but also were more consistent in body-weight judgments about themselves across a variety of semantic and imaginal stimuli (Markus, Hamill, \& Sentis, 1987). In addition, the availability of an overweight selfschema impacted judgments about the desirability of food. Although both those with an overweight self-schema and those without rated a similarly large percentage of foods as desirable to eat, those with an overweight schema spent more time making their ratings. These findings suggest that the availability of a body-weight self-schema not only impacts the processing of information about one's body size and shape but also plays a role in decisional processes involving food.

The body-weight self-schema provides a useful 
theoretical framework for explaining the bodyimage disturbances associated with eating disorders. For example, the feelings of fatness and body-size overestimations associated with the disorders may be considered manifestations of the underlying overweight self-schema. The emaciated anorexic woman who complains of feeling fat and rates herself as larger than she objectively is, may be articulating proprioceptive information encoded within the self-schema at a point when she was objectively heavier, which is now reexperienced each time the body-weight self-schema is activated in working memory. The stable, enduring, if not resistant, nature of the self-schema (Markus, 1977; Stein, 1994) may account for why these feelings persist despite the obvious change in current body size. Similarly, the bingeing, purging, and other ritualistic eating and exercise behaviors can be viewed as the procedural knowledge that is stored within the self-schema and enacted each time the schema is activated.

\section{Accessibility of the Overweight Self-Schema}

A third feature of the self-concept that may distinguish women with eating disorders from other populations of women may be the accessibility of the body weight schema. Although many women within the American weight-conscious culture may have an overweight self-schema available in memory (Rodin, Silberstein, \& Streigel-Moore, 1985), an important distinction between those women who engage in mild dysregulated eating behaviors and those with true eating disorders may be the frequency with which the overweight schema is activated and used as the organizing framework in information processing.

Self-schemas are chronically accessible cognitions. Studies have shown that self-schemas are automatically activated and exert a powerful influence over the processing of self-relevant information (Markus, 1977; Markus, Hamill, \& Sentis, 1987). Given the fact that all self-schemas are chronically accessible, what factors distinguish women with eating disorders from other women with overweight body self-schemas?

For most women, an overweight body selfschema may be only one of a broader collection of positive self-schemas accessible in working memory. The diverse collection of accessible selfschemas means that each stimulus encountered could be examined for a match to one of multiple frameworks, and therefore a variety of interpretations may be possible. In contrast, a woman with an overweight schema who has few other selfschemas accessible is likely to use the overweight schema as the interpretative framework for a broader array of self-relevant stimuli (Vitousek \& Hollon, 1990). The repeated use of the overweight selfschema will, in turn, serve to further heighten the accessibility of the structure and lead to further entrainment of variety of stimuli to the schema (Higgins \& King, 1981).

Changes in the woman's capacity for active processing may also heighten the accessibility of the overweight body self-schema. A widely accepted view of human information processing suggests that people have two distinctly different types of attentional processes available (Butter, 1987; Higgins \& King, 1981; van Zomeren \& Brouwer, 1994). The first type, referred to as active processing, is the conscious, goal-directed perception and processing of stimuli. Active processing is intentional. When in this mode of functioning, the individual purposively focuses and sustains attention on a stimulus event and is aware of its analysis and interpretation. Active processing also is considered an effortful mental activity (Clark, Geffen, \& Geffen, 1987). It is dependent on the activation of neural inhibitory mechanisms that block distracting and competing stimuli (Posner \& Snyder, 1975). It is the inhibitory processes that are viewed as central to the person's ability to sustain purposeful focused attention on an stimulus event (Cimprich, 1992a).

The second type of processing, passive processing, refers to stimulus-controlled activation of a cognitive structure (Butter, 1987; Higgins \& King, 1981; vonZomeren \& Brouwer, 1994). Rather than being under the purposeful and effortful control of the person, passive processing is unintentional, uncontrollable, and requires little cognitive effort. Although self-schemas and other cognitions may be purposively activated, most often they are considered a part of the passive processing system that become strongly associated with relevant stimuli and are automatically used as the processing framework whenever the stimuli are encountered (Bargh \& Pratto, 1986). Studies have shown that situations that demand great attention lead to mental fatigue and a decreased capacity for active processing (Cimprich, 1992b). One important consequence of mental fatigue is decreased efficiency 
of the inhibitory mechanisms, which leads to greater difficulty suppressing automatic cognitive processes (Bargh \& Thein, 1985; Cimprich, 1992a).

During periods when active processing functions are intact, a woman with an overweight-body self-schema may be able to suppress activation of that self-schema and direct her attention to other relevant stimuli in the environment. In other words, she may be able to inhibit activation of the overweight schema to bring other frameworks to bear in the processing of an event. However, during periods of cognitive fatigue, active processing functions may be diminished and her ability to suppress activation of the overweight self-schema severely reduced.

This formulation of diminished active processing and resultant chronic accessibility of the bodyweight schema is consistent with findings that suggest that the onset of eating disorder behaviors is often associated with a major precipitating event (Garfinkel \& Garner, 1983). A major life event is likely to be associated with many attentiondemanding stimuli, which can lead to mental fatigue (Cimprich, 1992b) and a diminished ability to suppress the already highly accessible overweight self-schema. Chronic activation of the overweight schema and the associated procedural routines, in turn, are likely to set in motion the cycle of food-restricting or other eating-disorder behaviors. Hunger, starvation, and other related physiological changes caused by the eating-disorder behaviors may serve as additional stressors, which further contributes to the diminished inhibitory mechanisms (Fox, 1981; Laessle, Bossert, Hank, Hahleweg, \& Pirke, 1990), and a circular, reciprocal process may be set in motion.

\section{IMPLICATIONS FOR RESEARCH AND PRACTICE}

Use of the self-schema model as a theoretical approach to the self-concept in eating disorders has several advantages that may be important to advancing empirical and clinical knowledge in the field. First, the less abstract and more concise theoretical definitions of the components of the self-concept have made the development of valid and reliable methods of measurement possible (Stein, 1995b). Currently, a number of self-report questionnaires and card-sorting procedures are available to measure the contents and organization of the total self-concept. With the theoretical and operational definitions derived from the model, constructs such as identity and self-definition can be more precisely defined and measured and important clinically derived theories can be empirically tested. In addition, information-processing measures, such as incidental recall, response latency time for selfdescriptive endorsements, and intrusions of nonpresented materials, have been used to assess both the availability and accessibility of self-schemas in specific behavioral domains (Markus \& Sentis, 1982). These latter techniques may be particularly valuable, because they measure automatic, nonconscious indicators of the cognitions and therefore, may less likely to be affected by extraneous factors such as subject motivation and experimental demand (Segal, 1988).

A second important advantage of the selfschema model is that it provides a means of accounting for body-weight concerns and dysregulated eating behaviors of varying levels of severity. A widely acknowledged point within the eatingdisorder literature is that within our contemporary society, concerns about body size and shape are not restricted to women with $\mathrm{AN}$ and $\mathrm{BN}$. In fact, some have argued that dieting, weight concerns, and feeling "fat" are so pervasive, even among women of normal weight, that they may be considered normative (Rodin, Silberstein, Streigel-Moore, 1985). Yet despite the epidemic proportions of women of all ages who struggle with weightrelated concerns, many, if not most of them, will never develop the clinical syndromes of $\mathrm{AN}$ or $\mathrm{BN}$. Using the schema model, it is possible to look more broadly across the multiple dimensions of the self-concept and consider how these various dimensions function together in the formation of the disorders. For example, in the preliminary model, it is posited that a unique constellation of selfconcept deviations are necessary for the development of a more serious and chronic pattern of eating-disorder behaviors. Whereas the availability in memory of an overweight-body self-schema may lead to feelings of fatness, concern about body weight, and food, the co-occurrence of an impoverished field of positive self-schemas, along with changes in active and passive processing capacities, must occur for the body-weight schema to become the single most compelling source of self-definition and guide for action.

A third advantage of the self-schema model is 
that it provides an important theoretical linkage for explaining how the sociocultural environment exerts influence on the individual's beliefs and behaviors. Cognitive approaches to psychopathology, particularly depression, have been criticized for their failure to take into account the richness of the interchange between the person and the environment (Coyne, 1992). Actual negative aspects of the person's environment, such as marital problems or loss, and the negative consequences of the person's interpersonal style on the environment, which most likely contribute to both the onset and maintenance of depressive symptomology, typically are unaddressed. Given that a main tenet of the schema model is that cognitions about the self are a product of the sociocultural environment, formed and modified through interpersonal interactions (Markus \& Kitayama, 1991; Stewart \& Healy, 1989), the model provides a means for explaining how environmental transactions are internalized into personal beliefs and goals. Within this framework, the self-schemas may be considered the critical mediating variables for explaining how aspects of the immediate interpersonal and broader sociocultural environments - either in the form of cultural standards for female beauty (Rodin, Silberstein, \& Streigel-Moore, 1985), persistent teasing by peers (Thompson \& Heinberg, 1993), or controlling, perfectionistic parental standards (Bruch, 1973)impact processes of self-regulation and behavior (Cantor, 1990; Markus \& Wurf, 1987).

Finally, the value of the self-schema model as a theoretical framework in eating disorders ultimately rests on the extent to which it can be used to generate effective intervention strategies. Currently, interventions on the self-concept in eating disorders focus on changing faulty beliefs about one's body weight and shape (Butters \& Cash, 1987; Fairburn, 1985; Garner \& Bemis, 1982; Wooley \& Kearney-Cook, 1986). The schema model holds the potential for extending that focus to other structural and functional properties of the self-concept. For example, if empirical evidence is accrued to support the preliminary model outlined above, then in addition to focusing on changes in the content of the body-weight self-schema, interventions may also profitably focus on modifying its chronic accessibility. In this case, interpersonal interactions that focus on food and body weight might be discouraged, and even treatment strategies such as food diaries and meal planning could be reevaluated for their effects on the accessibility of body-weight schema. Another strategy to decrease the accessibility of the body-weight schema may be to facilitate the elaboration of other sources of self-definition. Building on the view that women with an eating disorder lack a clear self-definition and hence, a source of positive self-esteem (Bruch, 1973; Garner \& Garfinkel, 1981), an important focus of therapy may be on the construction of new self-schemas. Rather than striving to change existing negative cognitions about one's body weight, interventions aimed at identifying unacknowledged personal strengths and elaborating them into valued sources of self-definition may be an important strategy for diminishing the accessibility of the body-weight self-definition and improving confidence and self-esteem.

In summary, the self-concept has been broadly recognized a key factor in the onset and maintenance of the symptoms associated with $\mathrm{AN}$ and $B N$. For more than three decades, investigators from diverse orientations have argued that the person's attitudes, beliefs, and thoughts about the self are critical in understanding the disorders. Continued advances in understanding the role of the self-concept in eating disorders, however, rest firmly on our ability to integrate the rapidly growing body of knowledge about the self-concept into our work. The self-schema model is a rich and promising theoretical framework that holds the potential for strengthening not only our understanding but also our effectiveness in dealing with these grave and debilitating illnesses.

\section{REFERENCES}

American Psychiatric Association (1993). Practice guideline for eating disorders. American Journal of Psychiatry, 150, 207-228.

American Psychiatric Association (1994). Diagnostic and statistical manual of mental disorders (4th ed.). Washington, DC: Author.

Askevold, F. (1975). Measuring body image. Psychotherapy Psychosomatic, 26, 71-77.

Attie, I., \& Brooks-Gunn, J. (1989). Development of eating problems in adolescent girls: A longitudinal study. Developmental Psychology, 25, 70-79.

Bargh, J.A., Lombardi, W.J., \& Higgins, T.E. (1988). Automaticity of chronically accessible constructs in person $x$ situation effects on person perception: It's just a matter of time. Journal of Personality and Social Psychology, 55, 599-605.

Bargh, J., \& Pratto, F. (1986). Individual construct accessibility and perceptual selection. Journal of Experimental Social Psychology, 22, 293-311. 
Bargh, J., \& Thein, R. (1985). Individual construct accessibility, person memory, and the recall-judgment link: The case of information overload. Journal of Personality and Social Psychology, 49, 1129-1146.

Beck, A.T. (1967). Depression: Clinical, experimental and theoretical aspects. New York: Harper.

Boskind-Lodahl, M. (1976). Cinderella's stepsisters: A feminist perspective on anorexia nervosa and bulimia. Signs: Journal of Women in Culture and Society, 2, 342-356.

Bruch, H. (1973). Eating disorders: Obesity, anorexia nervosa, and the person within. New York: Basic Books.

Bruch, H. (1979). Developmental deviations in anorexia nervosa. Israel Annals of Psychiatry and Related Disciplines, 17, 255-261.

Bruch, H. (1981). Developmental considerations of anorexia nervosa and obesity. Canadian Journal of Psychiatry, 26, 212-217.

Bruch, H. (1982). Anorexia nervosa: Therapy and theory. American Journal of Psychiatry, 139, 1531-1538.

Bruch, H. (1985). Four decades of eating disorders. In D. Garner, \& P. Garfinkel (Eds.), Handbook of psychotherapy for anorexia and bulimia (pp. 7-18). New York: Guilford Press.

Bruner, J. (1957). On perceptual readiness. Psychological Review, 64, 123-152.

Butter, C. (1987). Varieties of attention and disturbances of attention: A neuropsychological analysis. In M. Jeannerod (Ed.), Neurophysiological and neuropsychological aspects of spatial neglect (pp 1-23). North-Holland: Elsevier Science Publishers.

Butters, J., \& Cash, T. (1987). Cognitive-behavioral treatment of women's body-image dissatisfaction. Journal of Consulting and Clinical Psychology, 55, 889-897.

Caire, J. (1994). The self as a mental model: An expert-novice approach. Unpublished manuscript.

Cantor, N. (1990). From thought to behavior: "Having" and "doing" in the study of personality and cognition. American Psychologist, 45, 735-750.

Cantor, N., \& Kihlstrom, J.F. (1987). Personality and social intelligence. Englewood Cliffs, NJ: Prentice-Hall.

Cash, T. \& Brown, T. (1987). Body image in anorexia nervosa and bulimia nervosa. Behavior Modification, 11, 487-521.

Casper, R.C., Halmi, K.A., Goldberg, S.C., Eckert, E.D., \& Davis, J.M. (1979). Disturbances in body image estimation as related to other characteristics and outcome in anorexia nervosa. British Journal of Psychiatry, 134, 60-66.

Cimprich, B. (1992a). A theoretical perspective on attention and patient education. Advances in Nursing Science, 14, 39-51.

Cimprich, B. (1992b). Attentional fatigue following breast cancer surgery. Research in Nursing \& Health, 15, 199-207.

Clark, C., Geffen, G., \& Geffen, L. (1987). Catecholamines and Attention II: Pharmacological studies in normal humans. Neuroscience \& Biobehavioral Reviews, 11, 353-364.

Cooper, P.J., \& Taylor, M.J. (1988). Body image disturbance in bulimia nervosa. British Journal of Psychiatry, 153, $32-36$.

Coyne, J. (1992). Cognition in depression: A paradigm in crisis. Psychological Inquiry, 3, 232-234.
Crisp, A.H., \& Kalucy, R.S. (1974). Aspects of the perceptual disorder in anorexia nervosa. British Joumal of Medical Psychology, 47, 349-361.

Deux, K. (1991). Social identities: Thoughts on structure and change. In R.C. Curtis (Ed.), The relational self: Theoretical convergences in psychoanalysis and social psychology (pp. 77-93). New York: Guilford.

Drewnowski, A., Yee, D.K., \& Krahn, D.D. (1988). Bulimia in college women: Incidence and recovery rates. American Journal of Psychiatry, 145, 753-755.

Fabian, L., \& Thompson, K. (1989). Body image and eating disturbance in young females. Intemational Journal of Eating Disorders, 8, 63-74.

Fairburn, C.G. (1985). Cognitive-behavioral treatment for bulimia. In D.M. Garner, \& P.E. Garfinkel (Eds.), Handbook of psychotherapy for anorexia nervosa and bulimia (pp. 160-192). New York: Guilford Press.

Fairburn, C., \& Garner, D. (1986). The diagnosis of bulimia nervosa. International Journal of Eating Disorders, 5 , 403-419.

Fava, M., Copeland, P., Schweiger, U., \& Herzog, D. (1989). Neurochemical abnormalities of anorexia nervosa and bulimia nervosa. American Journal of Psychiatry, 146, 963-971.

Fisher, M., Golden, N., Katzman, D., Kreipe, R., Rees, J., Schebendach, J., Sigman, G., Ammerman, S., \& Hoberman, H. (1995). Eating disorders in adolescents: A background paper. Journal of Adolescent Health, 16, 420-437.

Fox, C.F. (1981). Neutopsychological correlates of anorexia nervosa. International Journal of Psychiatry in Medicine, $11,285-290$.

Franks, M. (1994). Self-making and well-being. Paper presented at the 47th Annual Meeting of the Gerontological Society of America, Atlanta, GA.

Garfinkel, P.E., \& Garner, D.M. (1983). The multidetermined nature of anorexia nervosa. In P. Garfinkel, \& D. Garner (Eds.), Anorexia Nervosa: Recent developments in research (pp. 3-14). New York: Alan R. Liss.

Garner, D.M., \& Bemis, K.M. (1985). Cognitive therapy for anorexia nervosa. In D.M. Garner, \& P.E. Garfinkel (Eds.), Handbook of psychotherapy for anorexia nervosa and bulimia (pp. 107-146). New York: Guilford Press.

Garner, P.E., \& Garfinkel, P. (1981). Body image in anorexia nervosa: Measurement, theory, and clinical implications. International Journal of Psychiatry in Medicine, 11, 263-283.

Glucksman, M.L., \& Hirsch, J. (1969). The response of obese patients to weight reduction: III. The perceptions of body size. Psychosomatic Medicine, 31, 1-7.

Goldfried, M., \&. Robins, C. (1983). Self-schema, cognitive bias, and the processing of therapeutic experiences. In P. Kendall (Ed.), Advances in cognitive-behavioral research and therapy: Vol. 2. (pp. 33-80). New York: Academic Press.

Gordon, R.A. (1990). Anorexia and bulimia: Anatomy of a social epidemic. Cambridge, MA: Basil Blackwell.

Greenwald, A.G. (1980). The totalitarian ego: Fabrication and revision of personal history. American Psychologist, 35 , 603-618. 
Greenwald, A.G., \& Pratkanis, A.R. (1984). The self. In R.S. Wyer, \& T.K. Srull (Eds.), Handbook of social cognition (pp. 129-178). Hillsdale, NJ: Erlbaum.

Halmi, K.A. (1987). Anorexia nervosa and bulimia. Annual Review of Medicine, 38, 373-380.

Harter, S. (1990). Causes, correlates and the functional role of self-worth: A life-span perspective. In R.J. Sternberg, \& J. Kolligian (Eds.), Competence considered (pp. 67-97) New Haven, CT: Yale University Press.

Harter, S., \& Monsour, A. (1992). Developmental analysis of conflict caused by opposing attributes in the adolescent self-portrait. Developmental Psychology, 28, 251-260.

Herzog, D. (1992). Eating disorders: New threats to health. Psychosomatics, 33, 10-15.

Higgins, T.E., \& King, G. (1981). Accessibility of social constructs: Information-processing consequences of individual and contextual variability. In N. Cantor, \& J.F. Kihlstrom (Eds.), Personality, cognition, and social interaction (pp. 69-121). Hillsdale, NJ: Erlbaum.

Hooker, K., \& Kaus, C. (1992). Possible selves and health behaviors in later life. Journal of Aging and Health, 4, 390-411.

Horne, R.L., Van Vactor, J.C., \& Emerson, S. (1991). Disturbed body image in patients with eating disorders. American Journal of Psychiatry, 148, 211-215.

Hsu, L.K.G. (1982). Is there a disturbance of body image in anorexia nervosa? Journal of Nervous and Mental Disease, 170, 305-307.

Huon, G., \& Brown, L.B. (1984). Psychological correlates of weight control among anorexia nervosa patients and normal girls. British Journal of Medical Psychology, 57, 61-66.

Keeton, W., Cash, T., \& Brown, T. (1990). Body image or body images: Comparative, multidimensional assessment among college students. Journal of Personality Assessment, 54, 213-230.

Kendzierski, D. (1988). Self-schemata and exercise. Basic and Applied Social Psychology, 9, 45-59.

Laessle, R.G., Bossert, S., Hank, G., Hahlweg, K., \& Pirke, K.M. (1990). Cognitive performance in patients with bulimia nervosa: Relationship to intermittent starvation. Biological Psychiatry, 27, 549-551.

Linville, P. (1987). Self-complexity as a cognitive buffer against stress-related illness and depression. Journal of Personality and Social Psychology, 52, 663-676.

Lucas, A., Beard, O'Fallon, W., \& Kurland, M. (1991). 50-year trends in the incidence of anorexia nervosa in Rochester, MN: A population-based study. American Journal of Psychiatry, 148, 917-922.

Markus, H. (1977). Self-schemas and processing information about the self. Joumal of Personality and Social Psychology, 35, 63-78.

Markus, H. (1990). Unresolved issues of self-representation. Cognitive Therapy and Research, 40, 241-253.

Markus, H., Crane, M., Bernstein, S., Siladi, M. (1982). Self-schemas and gender. Journal of Personality and Social Psychology, 42, 38-50.

Markus, H., Cross, S., \& Wurf, E. (1990). The role of the self-system in competence. In R.J. Sternberg, \& J.
Kolligian, (Eds.), Competence considered. New Haven, CT: Yale University Press.

Markus, H., Hamill, R., \& Sentis, K. (1987). Thinking fat: Self-schemas for body weight and the processing of weight relevant information. Journal of Applied Social Psychology, 17, 50-71.

Markus, H.R., \& Kitayama, S. (1991). Culture and the self: Implications for cognition, emotion, and motivation. Psychological Review, 98, 224-253.

Markus, H., \& Kunda, Z. (1986). Stability and malleability in the self-concept in the perception of others. Journal of Personality and Social Psychology, 51, 1-9.

Markus, H., \& Nurius, P. (1986). Possible selves. American Psychologist, 41, 954-969.

Markus, H., \& Sentis, K. (1982). The self in social information processing. In J. Suls (Ed.), Social psychological perspectives on the self (pp. 41-70). Hillsdale, NJ: Erlbaum.

Markus, H., Smith, J., \& Moreland, R. (1985). Role of the self-concept in the perception of others. Journal of Personality and Social Psychology, 49, 1494-1512.

Markus, H., \& Wurf, E. (1987). The dynamic self-concept: A social psychological perspective. In M.R. Rosenweig, \& L.W. Porter (Eds.), Annual Review of Psychology, 38, 299-337.

Markus, H., \& Zajonc, R.B. (1985). The cognitive perspective in social psychology, In G. Lindzey \& E. Aronson (Eds.), Handbook of social psychology (pp. 137-229), 3rd Edition. New York: Random House.

Marsh, H.W. (1986). Global self-esteem: Its relation to specific facets of self-concept and their importance. Journal of Personality and Social Psychology, 51, 1224-1236.

Marsh, H.W., \& Richards, G.E. (1988). Tennessee Self-Concept Scale: Reliability, internal structure, and construct validity. Journal of Personality and Social Psychology, 55, 612-624.

Meermann, R., Vandereycken, W., Napierski, C. (1986). Methodological problems of body image research in anorexia nervosa patients. Acta Psychiatrica Belgica, 86, 42-51.

Palla, B., \& Litt, I.F. (1988). Medical complications of eating disorders in adolescents. Pediatrics, 81, 613-623.

Patton, G.C. (1988). Mortality in eating disorders. Psychological Medicine, 18, 947-951.

Pelham, B.W., \& Swann, W.B. (1989). From self-conceptions to self-worth: On the sources and structure of global self-esteem. Journal of Personality and Social Psychology, 57, 672-680.

Polivy, J. \& Herman, P. (1985). Dieting and bingeing: A causal analysis. American Psychologist, 40, 193-201.

Posner, M., \& Synder, C. '(1975). Attention and cognitive control. In R.L. Solso (Ed.), Information processing and cognition (pp. 55-85). Hillsdale, NJ: Erlbaum.

Rodin, J., Silberstein, L., \& Streigel-Moore, R. (1985). Women and weight: A normative discontent. Nebraska Symposium on Motivation (vol. 32, pp. 267-307). Lincoln: University of Nebraska Press.

Rosen, J.C. (1990). Body-image disturbances in eating disorders. In T.F. Cash, \& T. Pruzinsky (Eds.), Body images: Development, deviance, and change (pp. 190-213). New York: Guilford Press. 
Rosenberg, M. (1965). Society and the adolescent self-image. New Jersey: Princeton University Press.

Schlundt, D.G., \& Johnson, W.G. (1990). Eating disorders. Assessment and treatment. Boston, MA: Allyn \& Bacon.

Schupak-Neuber, E., \& Nemeroff, C. (1993). Disturbances in identity and self-regulation in bulimia nervosa: Implications for a metaphorical perspective of "body as self." International Journal of Eating Disorders, 13, 335-347.

Schilder, P. (1950). The image and appearance of the human body. New York: International Universities Press.

Segal, Z. (1988). Appraisal of the self-schema construct in cognitive models of depression. Psychological Bulletin, 103, 147-162.

Sharp, C.W., \& Freeman, C.P. (1993). The medical complications of anorexia nervosa. British Journal of Psychiatry, $162,452-462$.

Showers, C. (1992). Compartmentalization of positive and negative self-knowledge: Keeping bad apples out of the bunch. Journal of Personality and Social Psychology, 62, 1036-1049.

Silver, R., Boon, C., \& Stone, M. (1983). Searching for meaning in misfortune: Making sense of incest. Journal of Social Issues, 39, 81-102.

Slade, P.D. \& Russell, M. (1973). Experimental investigation of body perception in anorexia nervosa and obesity. Psychotherapy Psychosomatic, 22, 359-363.

Stein, K.F. (1994). Complexity of the self-concept and responses to disconfirming feedback. Journal of Cognitive Therapy and Research, 18, 161-178.

Stein, K.F. (1995a). The organizational properties of the selfconcept and instability of affect. Research in Nursing and Health, I8, 405-415.

Stein, K.F. (1995b). The schema model of the self-concept. Image, 27, 187-193.

Stein, K.F., \& Markus, H. (1990). The self-structure: An assessment of the organizational properties. Paper presented at the American Psychological Association, Boston, MA.

Stein, K.F., Markus, H., \& Roeser, R. (1995). The sociocultural shaping of self-esteem of American adolescent girls and boys. Unpublished manuscript.

Stewart, A., \& Healy, J. (1989). Linking individual development and social change. American Psychologist, 44, 30-42.

Streigel-Moore, R., McAvay, G., \& Rodin, J. (1986). Psychological and behavioral correlates of feeling fat in women. International Journal of Eating Disorders, 5, 935-947.

Striegel-Moore, R.H., Silberstein, L.R., \& Rodin, J. (1986). Toward an understanding of risk factors for bulimia. American Psychologist, 41, 246-263.

Strober, M. (1981). The significance of bulimia in juvenile anorexia nervosa: An exploration of possible etiologic factors. International Journal of Eating Disorders, I1, $28-43$.

Strober, M. (1991). Disorders of the self in anorexia nervosa: An organismic-developmental paradigm. In C. Johnson (Ed.),
Psychodynamic treatment of anorexia nervosa and bulimia (pp. 354-373). New York: Guilford Press.

Strober, M., Goldenberg, I., Green, J., \& Saxon, J. (1979). Body image disturbance in anorexia nervosa during the acute and recuperative phase. Psychological Medicine, 9, 695-701.

Taylor, S.E., \& Crocker, J. (1981). Schematic bases of social information processing. In E.T. Higgins, C.P. Herman, \& M.P. Zanna (Eds.). Social cognition: The Ontario Symposium (pp. 39-88). Hillsdale, NJ: Erlbaum.

Theander, S. (1985). Outcome and prognosis in anorexia nervosa and bulimia nervosa: Some results of previous investigations, compared with those of a Swedish longterm study. Journal of Psychiatric Research, 19, 493-508.

Thompson, B. (1994). A hunger so wide and so deep: American women speak out on eating problems. Minneapolis: University of Minnesota Press.

Thompson, J.K., \& Heinberg, L. (1993). Preliminary test of two hypotheses of body image disturbance. International Journal of Eating Disorders, 14, 59-63.

Toner, B., Garfinkel, P.E., \& Garner, D.M. (1986). Long-term follow-up of anorexia nervosa. Psychosomatic Medicine, 48, 520-529.

Touyz, S., \& Beumont, P., \& Collins, J. (1988). Does over- or underestimation of body shape influence response to treatment in patients with anorexia nervosa? International Journal of Eating Disorders, 7, 687-691.

van Zomeran, \& Brouwer, W. (1994). Clinical neuropsychology of attention. New York: Oxford University Press.

Vitousek, K., \& Hollon, S. (1990). The investigation of schematic content and processing in eating disorders. Cognitive Therapy and Research, 14, 191-214.

White, J. (1991). Feminism, eating, and mental health. Advances in Nursing Science, 13, 68-80.

Williams, G., Powers, K., Millar, H., Freeman, C., Yellowless, A., Dowds, T., Walker, M., Campsie, L., MacPherson, F., Jackson, M. (1993). Comparison of eating disorders and other dietary/weight groups on measures of perceived control, assertiveness, self-esteem, and self-directed hostility. International Journal of Eating Disorders, 14, $27-32$.

Wooley, S., \& Kearney-Cooke, A. (1986). Intensive treatment of bulimia and body-image disturbance. In K.D. Brownell, \& J.P. Foreyt (Eds.), Handbook of eating disorders (pp. 476-502). New York: Basic Books.

Wooley, S., \& Wooley, W. (1985). Intensive outpatient and residential treatment. In D. Garner \& P. Garfinkel (Eds.), Handbook of psychotherapy for anorexia nervosa and bulimia nervosa (pp. 391-430). New York: Guilford Press.

Woolfolk, R., Novalany, J., Gara, M., Allen, L., \& Polino, M. (1995). Self-complexity, self-evaluation, and depression: An examination of form and content within the self-schema. Journal of Personality and Social Psychology, 68, 1108-1120. 